\title{
Uma noite, Markovitch, de Ayelet Gundar-Goshen
}

GUNDAR-GOSHEN, Ayelet. Uma noite, Markovitch. Tradução: Paulo Geiger. São Paulo: Todavia, 2018. 397 p.

Marian Gabani Gimenez*

O primeiro romance de Ayelet Gundar-Goshen, publicado em 2018 no Brasil, com tradução de Paulo Geiger, pela editora Todavia, é uma obra de fôlego que narra a trajetória de um grupo de judeus recém-imigrados à Palestina no período imediatamente posterior à Segunda Guerra Mundial, estabelecidos em uma pequena colônia marcada por uma constante tensão com os habitantes árabes da região e por seu alinhamento à ideologia sionista de Jabotinsky e da organização paramilitar Irgun.

Dividida em quatro partes com irônica pretensão temporal, entituladas "antes", "durante", "depois" e "depois de depois", a narrativa, em princípio, é centrada em Iaakov Markovitch e em Zeev Feinberg, companheiros que trabalham em defesa e no desenvolvimento da colônia em que vivem. São descritos como homens de aparência e personalidades diametralmente opostas - o primeiro, um rapaz sem qualquer singularidade física ou de personalidade e nenhum apelo com as mulheres, embora profundamente comprometido com a causa do Irgun, tendo seus comandantes e ideólogos em alta estima; o último, amplamente conhecido por seu volumoso e caricato bigode e por suas aventuras sexuais, que, por vezes, distraem-no do trabalho de vigia noturno nos arredores da colônia. Como resultado de uma dessas aventuras de Feinberg com a esposa do shochet local, Rachel Mandelbaum, os amigos recebem do vicecomandante do Irgun a proposta de uma breve viagem à Europa com a missão de se casarem com jovens judias europeias, retornando com elas para a Palestina, onde lhes concederiam o divórcio, no intuito de burlar as restrições migratórias impostas pelos mandatários britânicos.

Zeev Feinberg parte, então, na companhia de Iaakov Markovitch, ao continente europeu com a esperança de retornar em pouco tempo a uma colônia onde os ânimos do shochet traído estariam mais controlados e onde poderia, finalmente, conceder o divórcio à jovem europeia recém-imigrada e se casar com sua amada Sônia. Na Europa, Iaakov, para a surpresa de todos, é pareado com a jovem mais cobiçada do grupo e decide, no retorno à Palestina, não lhe conceder o divórcio, recusando-se a perfomar a cerimônia, mandatória no Judaísmo, para que os laços matrimoniais sejam desfeitos. A partir desse ato de Yaakov, visto como desleal à missão e ao Irgun, a colônia ganha uma nova configuração, acirrando as tensões entre os habitantes. $\mathrm{O}$ foco, que até então estava nas personagens de Iaakov e Zeev, torna-se mais difuso na narrativa, e descrições que beiram o arquetípico dão lugar a um mergulho nas complexas relações entre os habitantes da colônia.

Nos capítulos restantes da seção "antes”, que, entre outras possíveis interpretações, referese ao período anterior à Guerra da Independência e ao nascimento dos filhos de Iaakov e Zeev, acompanhamos as trajetórias individuais de cada uma das personagens, que culminarão na fundação de uma nova estrutura familiar e comunitária, base da vida dos colonos até o final do romance. As jornadas particulares se imbricam umas com as outras, criando teias de

\footnotetext{
*Bacharela em Letras (Hebraico) pela FFLCH-USP. Email: <marian-gabani@ hotmail.com>.
} 
relacionamentos que vão além dos triângulos amorosos entre Zeev, Sônia e o vice-comandante e entre Iaakov, Bela e o poeta. As figuras do vice-comandante e do poeta, por exemplo, ganham contornos muito mais humanizados do que sugeria a narrativa sionista dominante. Bela foge da casa de Iaakov para Tel Aviv, com a ajuda do vice-comandante, a fim de encontrar o poeta responsável pelas altas expectativas que nutria a respeito da Terra de Israel, simbolizadas pela laranja. No entanto, durante dois anos de relacionamento, que resultam em uma gravidez inesperada, o poeta revela-se tão decepcionante à jovem quanto o sabor da própria laranja e a vida na Palestina. As laranjas são, também, o elemento que conecta Sônia ao vice-comandante, cujas lealdades são postas em cheque diante dessa paixão arrebatadora pela esposa de Zeev, seu amigo e companheiro de movimento. Também esse affaire resulta em gravidez. $\mathrm{O}$ futuro da colônia - e, por metonínima, do Estado - está, portanto, nos ombros de filhos "ilegítimos", nascidos nesse entremeio complexo de relações.

O elemento heroico tão presente na narrativa de propaganda sionista, seja das linhas mais à esquerda quanto das mais à direita, não se sustenta na vida das personagens de GundarGoshen, tão carregadas de ambiguidades e dilemas. Há uma força irônica no fato de a primeira geração de sabras, no romance, serem nascidos de relacionamentos obscuros e não-normativos de um vice-comandante - e "vice", aqui, é bastante significativo - extremamente passional e de um poeta nacional fracassado. Há, ainda, duas outras crianças cujas origens também estão envoltas em ambiguidades: a menina, filha de nazistas, trazida por Zeev da sua missão de caça aos algozes nazistas, narrada mais adiante na seção "durante", e o filho de Rachel Mandelbaum, nascido em condições precárias unicamente com o auxílio de Iaakov Markovitch, até então tratado pelos outros colonos como um pária por sua deslealdade à missão do Irgun.

A fluidez e a ambiguidade das lealdades são intensificadas na seção seguinte do romance, intitulada "durante". Com o início da Guerra da Independência, os colonos homens são chamados a defender o Estado nascente e partem para a frente de batalha. $\mathrm{O}$ chamado ideológico, no entanto, perde força quando confrontado com os dilemas pessoais de cada um. Zeev é o primeiro, na narrativa, a ter suas convicções profundamente abaladas, ao atirar em uma mulher árabe que carregava uma criança. O que antes era sua função dentro do Irgun e da colônia torna-se um fardo psicológico e transforma sua relação com Sônia e com seu filho, agora marcada pelo afastamento e pela rejeição. Também o vice-comandante Efraim reconhece nos olhos do inimigo árabe sua dor pessoal, identificada como a dor de se perder alguém que lhe é muito precioso. Nem mesmo os louros da vitória e os bebês nomeados em sua homenagem são capazes de aplacar a tristeza de Efraim ao perceber que a criança que nascera de Sônia não seria jamais reconhecida como sua - ao menos não sem que sua deslealdade viesse a público. A dor do impasse do vice-comandante acaba por se traduzir na descrença no projeto do Estado: “Como seria possível este país ficar tranquilo?” (p. 225).

A vitória na guerra constrasta com o extenso inventário de perdas pessoais dos colonos. A casa de Rachel e Avraham Mandelbaum é a primeira a se esfacelar por completo. A colona, que, quando da sua imigração, decidira abandonar por completo o passado europeu e a língua alemã, volta a ser assombrada pelo som do crânio esmagado de um judeu atacado que presenciara em Viena. A guerra que Rachel acreditava haver deixado esquecida no passado torna-se cada vez mais presente, ao ponto de tornar-se insuportável. Ela, então, suicida-se. A 
reação intensa de Avraham ao encontrar a esposa morta leva os outros colonos julgar que havia enlouquecido em seu luto, e seu filho Iotam é entregue aos cuidados de Sônia e Zeev Feinberg.

Os Feinberg, por sua vez, trilham seus próprios caminhos para lidar com o luto e o trauma pós-guerra. Enquanto Sônia se muda a Tel Aviv para trabalhar primeiramente como secretária de Efraim e depois como recrutadora de mulheres para o Irgun, Zeev parte em mais uma missão na Europa, dessa vez para caçar oficiais nazistas em Berlim. Não há nele, entretanto, o sentimento vingativo ou a passionalidade que se esperaria de alguém disposto a acatar tal missão, mas a esperança de que se recupere do trauma de reconhecer a humanidade no inimigo que matara e de que retorne à Palestina como o homem que era antes da guerra. É a pequena Naama, filha de um oficial nazista assassinado pelo colega de missão de Zeev, que dá início a essa recuperação. Assombrado pela possibilidade de que o mesmo destino da mãe e do bebê árabe se abata sobre a criança, Zeev vira-se contra seu colega, denunciando-o à polícia alemã, e resolve se passar por pai da menina alemã, contando, inclusive, com a ajuda de um senhor que já forjara documentos durante o período nazista para proteger crianças judias. Novamente, são postas questões de lealdade, vínculos pessoais e identidades coletivas: Zeev alcança sua "expiação" (p. 257) ao escolher a bebê alemã de oficial nazista, em quem "corria sangue ariano puro" (p. 256), em detrimento da missão e de seu próprio colega, cujo único propósito era vingar o sofrimento dos judeus.

Iaakov Markovitch, antes tão apegado aos escritos de Jabotinsky, é movido, no campo de batalha, por sua paixão pessoal, Bela. Junto a outros dois soldados, cada um com sua motivação e obsessões pessoais em nada relacionadas aos valores nacionalistas seculares da guerra, ele é tido como alguém dotado da intensa passionalidade ideal para o combate. É sua paixão por Bela, a esposa que arrumara ao trair a missão que lhe fora incumbida pelo Irgun, que faz de Iaakov o único sobrevivente em sua frente de batalha. A vitória do lado israelense, no entanto, não é capaz de aplacar sua tristeza diante da morte de seus companheiros e da rejeição da mulher que mantera esposa à força.

Em paralelo, o contexto da guerra afeta Bela de modo bastante indireto, embora marcante. É nos poemas da falecida Rachel Mandelbaum, escritos em alemão, a língua das vidas passadas de ambas as colonas, que Bela experimenta novamente a mesma fascinação que sentia com os versos do poeta de Tel Aviv. Os poemas, que Bela resgatara do fogo com sua própria mão, revelam a permanência e a força do passado na vida de Rachel e o conflito entre as histórias pessoas dos imigrantes e a narrativa dominante da ideologia sionista. Essa tensão, que permeou sorrateiramente os dias de Rachel na Palestina, não se finda quando da sua morte. Ao contrário, torna-se o próprio luto de Bela: mesmo após traduzi-los ao hebraico, não há quem esteja disposto a publicar os poemas de alguém que tirara sua vida no mesmo dia da grande vitória dos judeus, nem ao menos a lê-los quando publicados de forma independente. Bela destrói, então, as 700 impressões do livro com o qual criara vínculos tão profundos.

O último capítulo de "durante" tem ares de conclusão. O narrador chama atenção para a construção da temporalidade do romance. Trajetórias estão sendo contadas, com particular foco em alguns momentos, e, embora o tempo objetivo transcorra linearmente - da juventude à velhice - os colonos não o vivem assim. Os eventos da vida de cada um, dos mais banais aos mais extraordinários, são cheios de insinuações do passado e de imbricações com o contexto político e com a coletividade. 
A seção "depois" tem como elemento central as trajetórias de Iair e Naama Feinberg e Tzvi Markovitch, filhos de Zeev e Iaakov. As crianças, nascidas no mesmo período que o Estado de Israel, vivem os anos de infância envoltos na atmosfera ideológica sionista, intensificada pela vitória na guerra e pela independência. A formação de suas subjetividades está, portanto, imbricada na formação do próprio modelo nascente do cidadão israelense. Ela não acontece, entretanto, sem tensões. A primeira é a descoberta si como diferente do outro: ocorre com Naama ao perceber que sua pele não compartilha o aroma de pêssego da de seu irmão; quando Iair e Tzvi, embora chamados de "gêmeos siameses" pelos colonos, recebiam tratamento distinto por parte dos professores; no momento em que se há a consciência de que Sônia tem Iair como filho preferido; quando Tzvi entende a jamais mencionada "femininilidade" (p. 342) de Naama. A descoberta da alteridade pelas crianças é, ainda, acompanhada pela formação de suas próprias identidades a partir de narrativas com pouco lastro na realidade. Se o leitor já conhece as complexas relações que trouxeram as personagens e a narrativa a esse ponto, as crianças têm acesso unicamente ao que lhes é dito a todo momento pelos adultos sobre o heroísmo, claramente romantizado, da guerra de outrora.

Iair, Tzvi e Naama decidem, então, tornar-se combatentes e sair em uma missão à cidade de Petra, na Jordânia, cruzando o uádi a pé. No dia seguinte, quando não encontram seus filhos, os pais, na companhia do vice-comandante, saem em busca das crianças, encontrando-as em grave estado de desidratação no deserto. Das três, Iair Feinberg é o único que não resiste e falece, para desespero de Zeev, Sônia e do vice-comandante, pai biológico do menino. Há no trágico acidente um ressonar das tensões e das perdas do período da guerra que evoca um movimento cíclico - a mesma narrativa ideológica que causara tanta dor e decepção nos colonos agora atinge seus filhos, e volta a atingir os pais. As páginas finais da seção, cheias de marcações temporais, tratam da morte do vice-comandante, cuja memória é constantemente preterida à memória de outros grandes da história do Estado. As crianças nomeadas outrora em sua homenagem seguiram suas trajetórias ou as tiveram interrompidas, todas elas, embora parte de uma história maior, um universo em si mesmas.

A seção final do romance, "depois de depois", narra os últimos dias de Iaakov Markovitch, dias em que nada de extraordinário ocorre, em que é somente parte da paisagem histórica da colônia. Não há nada de particularmente heroico ou grandioso em seu fim, apenas a efemeridade de uma vida que se entremeia a outras. As personagens de Uma noite, Markovitch não são os heróis modelo da literatura sionista dos anos de construção do Estado, tampouco são o contraponto ou o questionamento desse modelo, como a literatura hebraica traria alguns anos depois. São, antes, vidas que se desenrolam apesar da ideologia vigente, embora profundamente mergulhados nela, em uma dinâmica permeada por nuances, essencialmente humana. 